DOI 10.37882/2223-2982.2021.06-2.14

\title{
СТИЛИСТИЧЕСКИЕ ОСОБЕННОСТИ МОНОЛОГОВ В СКРИПТАХ РУССКОЙ И БРИТАНСКОЙ ЭКРАНИЗАЦИЙ РОМАНА Ф. М. ДОСТОЕВСКОГО «ПРЕСТУПЛЕНИЕ И НАКАЗАНИЕ»
}

\section{STYLISTIC FEATURES OF MONOLOGUES IN SCRIPTS OF RUSSIAN AND BRITISH ADAPTATIONS OF F. M. DOSTOEVSKY'S "CRIME AND PUNISHMENT"}

D. Kelesh

Summary: The article discusses the problem of using stylistic devices in monologues in script texts of Russian and British adaptations of F.M. Dostoevsky's "Crime and Punishment". The research topic relevance is due to the fact that the adaptation of world classics literature not only promotes the popularization among a wide audience, but also affects the perception of ideas expressed in these works by viewers form different linguistic cultures. The result of such perception at the mental-linguistic level depends on what kind of stylistic means are used in the scripts. The article presents the results of an empirical study based on a systematic methodological approach and on the two adaptations of the novel by F.M. Dostoevsky's "Crime and Punishment". The objectives of the study were to compare the stylistic means of monologues in scripts of both film versions using a technique that allows you to compare unpaired examples, regardless of the timing and framing of the film adaptation. As a result, the author of the article came to the following conclusions: in the Russian film version, the original rhythm of the characters' speech is largely preserved with the help of such stylistic techniques as lexical repetition, markers of colloquial speech and vulgarism, as well as mixing of speech styles.

Keywords: linguistics, stylistic devices, monologue, novel, film adaptation, script text.

\author{
Келеш Дарья Андреевна \\ Аспирант, Московский государственный областной \\ университет, г. Мытищи \\ solo.dar9294@yandex.ru
}

Аннотация: В статье рассматривается проблема использования стилистических приемов в монологах скриптов (текстов сценариев) русской и британской экранизаций романа Ф.М. Достоевского «Преступление и наказание». Актуальность темы исследования обусловлена тем, что экранизация произведений мировой классики не только способствует популяризации этих произведений среди широкой зрительской аудитории, но также влияет на восприятие идей, выраженных в этих произведениях, зрителями разных языковых культур. От того, какие именно стилистические средства используются в текстах сценариев, зависит конечный результат такого восприятия на ментально-языковом уровне. В статье представлены результаты эмпирического исследования, основанного на системном методологическом подходе и на материалах двух экранизаций романа Ф.М. Достоевского «Преступление и наказание». Задачи исследования заключались в сопоставлении стилистических средств монологов в скриптах обеих киноверсий с помощью методики, которая позволяет сравнивать непарные примеры, вне зависимости от тайминга и кадрирования экранизации. По итогу проведенного исследования автор статьи пришел к следующим выводам: в русской киноверсии в большей степени сохранен оригинальный ритм речи героев с помощью таких стилистических приемов, как лексический повтор, маркеры разговорной речи и вульгаризмы, а также смешение стилей речи.

Ключевые слова: лингвистика, стилистические приемы, монолог, роман, экранизация, текст сценария.

низации в целом. Эти тезисы особенно актуальны для произведений мирового значения, в том числе - для экранизаций романов великих русских писателей.

Для понимания темы исследования также необходимо обратить внимание на ключевое понятие, связанное с репрезентацией героев в экранизациях классических произведений, - драматический монолог.

Драматический монолог - это «разговор с самим собой, в ходе которого говорящий представлен драматически» [11, с.49]. Драматический монолог служит для выявления намерений персонажа в экранизации, театральной постановке или в радио-спектакле. С точки зрения стилистики, драматический монолог имеет свои особенности: 
1. Один персонаж, выступающий с речью об одном из аспектов своей жизни;

2. Аудитория может присутствовать, а может и не присутствовать в кадре или на сцене;

3. Персонаж раскрывает свой темперамент и характер в большей степени через речь.

В научной литературе исследователи выделяют следующие виды драматического монолога: романтический, философско-психологический и разговорный [8, с.622]. С точки зрения лингвистики, монолог - это инструмент, позволяющий высказать свои мысли. Монолог как форма выражения идеи дает писателям и драматургам возможность использовать весь спектр стилистических средств для репрезентации персонажа через его речь [10, с.168].

Стилистические средства монолога могут быть самыми разнообразными: повтор, метафора, смешение стилей речи, использование разговорных слов, фразеологизмов, вульгаризмов и т.п. [8, с.623].

При этом, для экранизации произведений классической литературы мирового значения перед сценаристом стоит непростая задача трансформации внутреннего монолога героя, который используется для раскрытия характера и мотивов персонажа писателем в прозаическом или поэтическом произведении, в драматический монолог, который является способом репрезентации героя для зрителя.

То есть, если внутренний монолог в романе нацелен на раскрытие характера героя для читателя, то драматический монолог в сценарии экранизации должен воздействовать на зрителя, дополняя трехмерное изображение героя на экране и проясняя мотивы его поступков. Классическая русская литература известна своим глубоким психологизмом, который часто выражен внутренними монологами героев [4, с.217].

Наиболее сильными по социально-философскому наполнению являются, несомненно, произведения Ф.М. Достоевского. Более того, процесс экранизаций его произведений считается в кинематографических кругах наиболее сложным именно из-за обилия внутренних монологов героев, которые необходимо адаптировать для зрителя, выстроить по времени фильма и при этом максимально полно сохранить стилистику и идеи писателя для каждого персонажа.

Тем не менее, несмотря на все трудности, с которыми сталкиваются сценаристы, экранизации произведений Ф. М. Достоевского продолжают появляться как в русском, так и в зарубежном кинематографе.

При этом сохранение оригинальной стилистики монологов героев является для сценариста основной задачей, поскольку, как отмечают кинематографисты, «Ф.М. Достоевский в кино - это прежде всего текст» [7, c.35].

Различия в передаче стилистики монологов персонажей в экранизациях разных стран заслуживают отдельного изучения, поскольку позволяют установить, насколько полно передана специфика оригинала в сценариях экранизаций на разных языках, в различных лингвокультурах [9, с.128].

Историография исследуемой темы достаточно обширна и включает в себя исследования как отечественных, так и зарубежных авторов.

Общие проблемы стилистики монологов в художественных текстах рассматриваются в работах таких отечественных авторов как Н.И. Никулина, Г.Н. Чеботарева, М.Н. Макеева [8], А.А. Донцова [4,5], С.Н. Ильченко [6].

В работе Н.А. Гончаровой рассматриваются стилистические особенности монологов на материале английского языка [3]. Выводы, приведенные данным автором, полезны для нашего исследования тем, что позволяют выявить критерии анализа англоязычных монологов в рамках исследуемой темы.

Проблематике особенностей монологов в литературном наследии Ф.М. Достоевского посвящен целый ряд работ как отечественных, так и зарубежных авторов.

В частности, специфике монологической речи в произведениях Ф.М. Достоевского посвящены работы таких авторов, как Н.А. Азаренко [1], Д.С. Гайдарова [2], Г. Маслова [14] и К.Н. Отеева [9]. В зарубежной историографии по данной теме выделяются работы таких авторов, как Ю.Д. Оюн [10], Чжао Цюлин [11], 12. Дж.М. Бланди [12], М. Галунис [13], Т. Паркс [15], Дж.Э. Робинсон [16].

Проблеме экранизаций произведений Ф.М. Достоевского также посвящено большое количество научных работ, среди которых можно отметить исследования Р.Н. Круглова [7], посвященные анализу сценаристики в рамках экранизаций русской классики за рубежом.

Тем не менее, несмотря на обширную историографию, до сих пор в научной литературе не предпринимался лингвистический анализ скриптов экранизаций русской и англоязычной киноверсий романа Ф.М. Достоевского «Преступление и наказание».

В настоящей статье нами представлен анализ скриптов (текстов сценария) экранизаций романа на двух языках, что позволяет дополнить существующую научную литературу по теме исследования и, в свою очередь, определяет научную новизну представленного в статье исследования. 


\section{Методы и материалы}

Методология исследования основана на системном подходе и включает в себя методы общенаучной группы (анализ, синтез, индукция, дедукция), а также ряд специальных методов: метод сопоставительного стилистического анализа и метод частотного анализа лексических единиц.

Методика исследования заключается в сопоставлении скриптов (текстов сценариев) на примерах двух киноверсий романа Ф.М. Достоевского «Преступление и наказание»: экранизация Льва Кулиджанова 1969 года и экранизация Джулиана Джаррольда 2002 года по трем критериям стилистических приемов, характерных для оригинальных текстов монологов героев Ф.М. Достоевского: лексический повтор; использование разговорный речи и вульгаризмов; смешение стилей речи.

Предложенная нами методика анализа стилистических приемов монологов в скриптах позволяет сопоставлять различные экранизации романа вне тайминга и кадрирования, которые в экранизациях не совпадают.

Для анализа нами было отобрано 150 примеров (генеральная совокупность). Методом механической выборки были отобраны 50 монологов в скриптах по критерию использования стилистических средств: повторы, разговорная речь и вульгаризмы, смешение речевых стилей.

\section{Результаты исследования}

По первому критерию - лексический повтор, - были выявлены следующие примеры в русской и англоязыч- ной экранизациях:

Как можно судить по данным таблицы 1, прием лексического повтора используется в обеих экранизациях и служит для передачи подавленного настроения героя, его неуверенности в себе, состояния беспокойства.

Лексический повтор используется для того, чтобы зритель сразу, с первой сцены понимал состояние героя: неуверенность в себе, нервозность, отсутствие собранности и рационального восприятия реальности.

Повтор как стилистический прием используется наиболее часто в монологах обеих киноверсий. В русском и британском сценариях этот стилистический прием используется наиболее часто, особенно в монологах главного героя, что позволяет передать его эмоциональное состояние (тревожность, неуверенность в себе, в правильности своих поступков и мыслей и т.п.). В британской версии повтор выражен в большей степени законченными фразами, в то время как в русском сценарии используются не только фразы, но и целостные предложения и отдельные слова, что создают иллюзию спонтанности речи главного героя, а также «эффект присутствия» зрителя при рождении важного для героя решения.

Представленные в таблице 2 примеры позволяют говорить о том, что смешение стилей, как прием, в монологах героев используется в обеих экранизациях, но для британской киноверсии более характерно смешение разговорного и литературного стиля, а для русской киноверсии - смешение разговорного и официально-делового устаревшего (милостивый государь, обрел, вкусил и пр.), что, вероятно, во времена Ф. М. Достоевского было характерным «профессиональным сленгом» отставных

Использование лексического повтора как стилистического приема в монологах героев

Таблица 1. на примере скриптов двух экранизаций.

\begin{tabular}{|c|c|}
\hline \multicolumn{2}{|c|}{ Лексический повтор } \\
\hline $\begin{array}{l}\text { Скрипт экранизации Льва Кулиджанова } \\
\text { (Россия, 1969) }\end{array}$ & $\begin{array}{c}\text { Скрипт экранизации Джулиана Джаррольда } \\
\text { (Великобритания, 2002) }\end{array}$ \\
\hline Пример & Пример \\
\hline $\begin{array}{l}\text { 1. Любопытно, чего люди больше всего боятся? А ведь нового шага, но- } \\
\text { вого собственного слова они больше всего боятся. } \\
\text { 2. А впрочем, я много болтаю. Оттого и ничего не делаю, что болтаю. } \\
\text { Пожалуй, оттого болтаю, что ничего не делаю. Это я в этот последний } \\
\text { месяц выучился болтать. } \\
\text { 3. Так, ради фантазии сам себя тешу. Игрушки...Да, пожалуй, что игрушки } \\
\text { 4. Я знаю, для кого это все делается! Но я эту жертву не приму! Не приму, } \\
\text { не приму! Не приму! } \\
\text { 5. Случалось ли испрашивать взаймы безнадежно? Случалось. То есть, } \\
\text { как безнадежно? }\end{array}$ & $\begin{array}{l}\text { 1. Am I really going to do this? Will I do this? Will I do this? Will I do this? } \\
\text { This. } \\
\text { 2. A ruble fifty. Take it or leave it. A ruble fifty? } \\
\text { 3. Give it back to me! Give me my licence back, please. } \\
\text { 4. I want your complete devotion. A leading light, darling. A leading light. } \\
\text { 5. After a fortune all at once, are you? Yes. I'm after a fortune all at once. } \\
\text { 6. I didn't do it. I didn't do it. } \\
\text { 7. No. I don't want it! I don't want it! } \\
\text { I don't want it! I don't want it. } \\
\text { 8. Because you're just a means to an end. You're not even a person. You're just } \\
\text { a piece of shit that } \\
\text { I had to wipe off my shoe so I could... }\end{array}$ \\
\hline
\end{tabular}


Использование смешения стилей речи как стилистического приема в монологах героев на примере скриптов двух экранизаций.

\begin{tabular}{|c|c|}
\hline \multicolumn{2}{|c|}{ Смешение стилей речи } \\
\hline $\begin{array}{l}\text { Скрипт экранизации Льва Кулиджанова } \\
\text { (Россия, 1969) }\end{array}$ & $\begin{array}{c}\text { Скрипт экранизации Джулиана Джаррольда } \\
\text { (Великобритания, 2002) }\end{array}$ \\
\hline Пример & Пример \\
\hline $\begin{array}{l}\text { 1. Разве я не знаю, как ты читаешь? Хвать туда, хвать сюда, лишь бы } \\
\text { суть понять. Нет, маменька, именно подробности я и запомнил хорошо. } \\
\text { 2. Представь положение честной девушки, которая согласилась } \\
\text { на свидание с ним, чтобы убедить господина Свидригайлова оста- } \\
\text { вить ее в покое и раскрыть ему глаза на безобразнейшую сущ- } \\
\text { ность его поведения как мужа и отца. [...] Побросали вещички в } \\
\text { мужицкую телегу... прогнали, как последнюю..Да, да, да! } \\
3 \text { Милостивый государь, многократный опыт. Бедность не порок, это } \\
\text { истина. И пьянство не добродетель, тем паче. Но нищета, милостивый } \\
\text { государь, нищета - порок! } \\
\text { 4. Скорби, скорби я искал на дне его. И вкусил. И обрел. А пожалеет } \\
\text { нас тот, кто всех пожалел, всех и вся понимал. }\end{array}$ & $\begin{array}{l}\text { 1. I hope this stuff fits. I have been hunting high and low. } \\
\text { 2. As in any sound economy, an individual success benefits everyone. Oh, balls! } \\
\text { 3. Now, the fellow who murdered the pawnbroker, he's different. } \\
\text { 4. He's not one of them. } \\
\text { 5. He didn't manage to get his hands on any of the actual cash. } \\
\text { 6. There's a lot I can forgive in a sick man, but not anything. Please meet my } \\
\text { cousin, Porfiry Petrovich, scourge of Petersburg's criminal classes. Examining } \\
\text { magistrate, actually. }\end{array}$ \\
\hline
\end{tabular}

Таблица 3.

Использование разговорной речи и вульгаризмов как стилистического приема в монологах героев на примере скриптов двух экранизаций.

\begin{tabular}{|c|c|}
\hline \multicolumn{2}{|c|}{ Разговорная речь и вульгаризмы } \\
\hline $\begin{array}{c}\text { Скрипт экранизации Льва Кулиджанова } \\
\text { (Россия, 1969) }\end{array}$ & $\begin{array}{c}\text { Скрипт экранизации Джулиана Джаррольда } \\
\text { (Великобритания, 2002) }\end{array}$ \\
\hline Пример & Пример \\
\hline $\begin{array}{l}\text { 1. Некстати. Дура она. Дура-то дура. } \\
\text { 2. А я оттуда. И уже пятую ночь. Забавник! Для ча не работаешь? Для ча } \\
\text { не служите, коль чиновник? } \\
\text { 3. Так вот, опять по такому же дельцу. } \\
\text { 4. Ты думаешь, продавец, что полуштоф твой мне всласть пошел? } \\
\text { 5. Эк вам Алена Ивановна страху-то задала. Совсем вы как ребенок при } \\
\text { ней. И сестра она вам сведенная, а какую силу взяла. } \\
\text { 6. Аль зайти? } \\
\text { 7. Зачем же было время назначать? Сама же, ведьма, час назначила. А } \\
\text { у меня крюк! }\end{array}$ & $\begin{array}{l}\text { 1. So, in fact, it was perfectly natural for me to suggest that we elope together } \\
\text { to Switzerland or America. } \\
\text { 2. You're still a creep. } \\
\text { 3. Which I think, to be perfectly frank, she rather liked. } \\
\text { 4. She reminds me to do something and then off she goes again. } \\
\text { 5. My wife kept me like I was a piece of treasure she'd stuffed in her pocket. }\end{array}$ \\
\hline
\end{tabular}

чиновников, не занимавших руководящих должностей.

Старо-книжный пафос в примере 4 русской версии служит для акцентирования состояния алкогольного опьянения, при котором многие герои Ф.М. Достоевского входят в состояние «возвышенной мысли» и выражаются соответственно. Евангельские мотивы особенно пафосно звучат в речи пьяного персонажа.

Эта характерная особенность русского сценария позволяет сохранить не только авторский текст для конкретного героя второго плана, но и создать атмосферу эпохи, в которой разворачивается действие фильма. Для британской версии такие пафосные выражения, связанные с Евангелием, темой православного христианского прощения и специфического национального сочувствия к пьяницам, не используются.
Состояние опьянения описывается более чем сухо, в формально-описательном ключе. Вся тирада персонажа о том, как он «испил скорби» в британской версии исключена совсем.

Русская версия, разумеется, гораздо более ближе к оригиналу, чем британская с чисто текстуальной точки зрения, хотя британские сценаристы также использовали выражения разговорной речи и смешивали стиль с литературным (выражения типа to get hands on; слова balls, fellow, stuff и др. внедрены в текст скрипта намерено, для передачи разговорной стилистики).

В примере 1 в таблице 3 мы видим, что вульгаризм усиливается с помощью лексического повтора, что функционально акцентирует негативное отношение героя к объекту, о котором он говорит в таких нелестных выра- 
жениях. По сути, в данном примере используется одновременно и повтор, и вульгаризм, но таких примеров крайне мало в русской версии сценария. Проведенный нами анализ показал, что русский сценарий содержит довольно много вульгаризмов, которые внедрены в речь персонажей для отражения их эмоционального состояния или для демонстрации их социального положения. Для британской версии использование вульгаризмов практически не характерно, вместо них чаще всего используется разговорная речь.

Таким образом, все собранные нами примеры позволяют сделать предварительный вывод: повторы присутствуют в обеих версиях как стилистический прием, разговорная речь используется в британской версии в большей степени, а в англоязычной преобладает разговорная речь, смешение стиля наблюдается в русскоязычной версии чаще, чем в англоязычной экранизации.

В британской экранизации монологи выполняют в большей степени информативную функцию, эмоциональную в той степени, которая «прилична» для британской национальной культуры речи, то есть текст в сценарии был адаптирован для английской лингвокультуры с учетом особенностей и правил речевого этикета. В русской версии сценаристы более свободно использовали все выразительные стилистические средства для отражения состояния, социального положения и философского мировосприятия героев.

При этом, в русской версии сценария были выявлены двойные приемы, такие как смешение разговорной речи с книжной устаревшей и официально-деловой устаревшей для воссоздания атмосферы времени действия, а также повтор вульгаризмов в некоторых ключевых сценах для акцентирования внимания зрителя на возрастающее беспокойство главного героя.

Для наглядности полученные результаты анализа были переведены в количественные показатели по кри- терию частотности использования каждого из трех стилистических приемов в монологах на примерах скриптов двух экранизаций (рисунок 1).

Частотность стилистических приемов в монологах скриптов экранизаций романа Ф.М. Достоевского «Преступление и наказание» (рисунок 1) дает возможность установить, что для русской киноверсии романа более характерны лексические повторы, вульгаризмы и смешение, по крайней мере, трех стилей речи, в то время как в тексте британского сценария преобладает более нейтральная разговорная лексика, в меньшей степени используются лексические повторы, а смешение стилей речи ограничивается комбинированием разговорной речи с литературным книжным.

\section{Выво $\Delta ы$}

Проведенное исследование позволяет сделать следующие выводы: в обеих киноверсиях романа «Преступление и наказание» сценаристы стремились передать с помощью драматического монолога героев их эмоциональное состояние. Однако, в русской версии сценария в большей степени сохранены особые маркеры времени - использование вульгаризмов и устаревших стилей речи, которые в большей степени отражают авторский замысел писателя, позволяют зрителю понять, какое социальное положение занимает персонаж, произносящий монолог, а также его эмоциональное, ментальное и психическое состояние.

Стилистический прием повтора распространен в обеих версиях, но очевидно, что данный прием, который так часто использовал Ф.М. Достоевский для монологов своих героев, более эффективен именно в сфере русского языка: повторы создают особый ритм русского слова, который не удалось воспроизвести в британском сценарии с помощью повтора английских слов и выражений. То есть прием повтора, который сохранен в британской киноверсии, не передает в полной мере авторский стиль

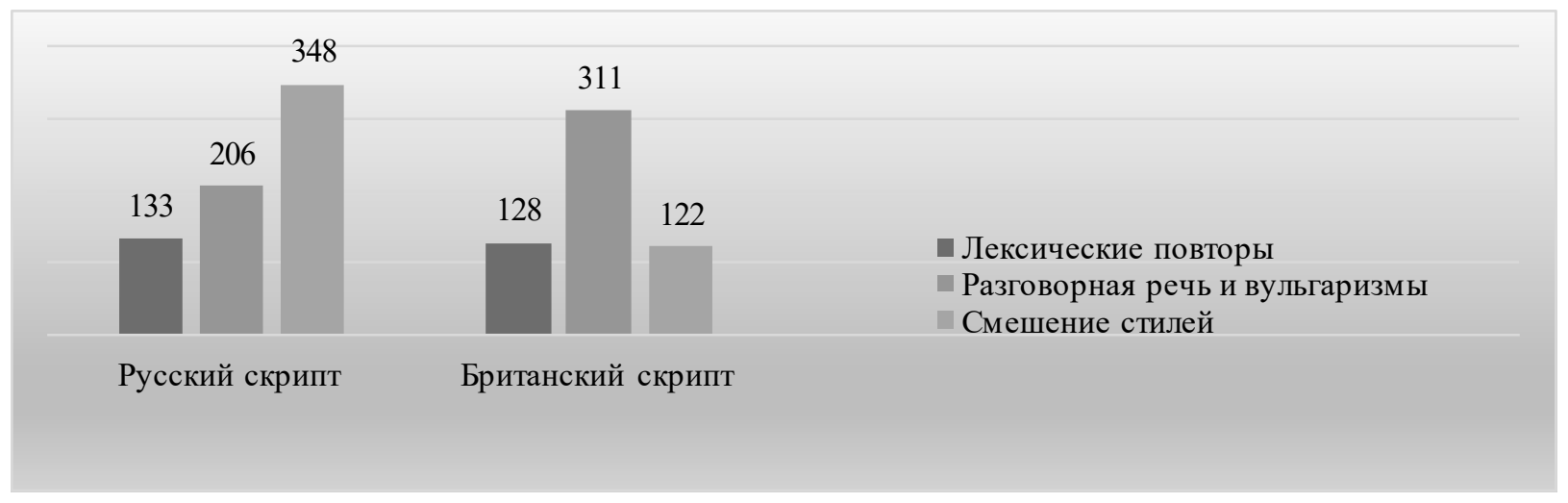

Рис. 1. Частотность использования лексических единиц стилистических приемов в русской и британской экранизациях романа Ф.М. Достоевского «Преступление и наказание» 
Ф.М. Достоевского, его уникальный «ритмический поток сознания, пульсацию мысли героя и его настроения». Разумеется, правы те исследователи, которые утверждают, что «охватить речевые приемы Достоевского можно только в их системном единстве, с учетом и пониманием их художественной функции» [14, с.80]. Полифония и ритм монологов героев Ф.М. Достоевского невозможно передать средствами другого языка, кроме русского. Как отмечают некоторые исследователи, «он не боялся длиннот и повторов, если они были необходимы для эмоционально-ритмического развития мысли, для полноты самовыражения героев, прибегал к особому виду сжатости фразы, достигая краткости большей, чем она возможна в нехудожественной речи» $[15$, с.25]. Эти два полюса стилистики Достоевского точно отмечены отечественными исследователями: «Речь Достоевского точно торопится и задыхается. Слова то громоздятся беспорядочной толпой, как будто мысль торопливо ищет себе выражения и не может схватить его, то обрывается коротко, резко, падают отрывистыми фразами, иногда одним словом, там, где грамматически было бы необходимо целое предложение» [11, с.52]. В русском сценарии все эти аспекты максимально были сохранены настолько, насколько это было возможно в ограниченном тайминге фильма.

На наш взгляд, следует продолжать исследование экранизаций романов русских писателей для понимания различий в текстах сценариев англоязычных и русскоязычных версий. Предложенная нами методика анализа позволяет сопоставлять стилистические особенности непарных примеров, избежать зависимости от кадрирования и тайминга киноматериала.

\section{ЛИТЕРАТУРА}

1. Азаренко Н.А. Триалог Ф.М. Достоевского как откровение писателя // Вестник Тамбовского университета. Серия: Гуманитарные науки. 2012. № 9. - С. 252-256.

2. Гайдарова Д.С. Психологизм в творчестве Ф.М. Достоевского // Гуманитарные, социально-экономические и общественные науки. 2016. № 5. - С. 48-56.

3. Гончарова Н.А. Национально-маркированные модели англоязычного текста и иноязычное образование // Технологии пищевой и перерабатывающей промышленности АПК - продукты здорового питания. 2014. № 4. - С. 88 -93.

4. Донцова А.А. Композиционно-структурирующий потенциал внутреннего монолога // Филологические науки. Вопросы теории и практики. 2019. № 5. C. 217-222.

5. Донцова А.А. Стратегии психологизации в аспекте экспликации экспрессивно-эмотивного пространства текста // Актуальные проблемы филологии и педагогической лингвистики. 2018. № 4. - С. 113-119.

6. Ильченко С.Н. Русская классика на телеэкране XXI века: новая реальность // Ученые записки Забайкальского государственного университета. Серия: Филология, история, востоковедение. 2015. № 2. - С. 83-88.

7. Круглов Р.Г. Интерпретация художественного мира Ф.М. Достоевского в фильме Р. Вине «Раскольников» // Вестник Санкт-Петербургского университета. Искусствоведение. 2015. № 2. - С. 34-45.

8. Никулина Н.И., Чеботарева Г.Н., Макеева М.Н. Авторские средства воздействия на реципиента в рамках внутреннего монолога (на материале романа /В. Вульф «Волны») // Вестник Тамбовского государственного технического университета. 2014. № 3. - С. 621-629.

9. Отева К.Н. О влиянии романа Ф.М. Достоевского «Преступление и наказание» на кинематограф Азии (Китай, Филиппины) // Известия Волгоградского государственного педагогического университета. 2017. № 9. - С. 126-130.

10. Оюн Ю.Д. Лингвостилистические средства передачи внутреннего монолога на материале французской художественной прозы XX века // Вестник Тувинского государственного университета. Социальные и гуманитарные науки. 2017. № 1. - С. 167-173.

11. Чжао Цюлин. Анализ полифонии романа Ф.М. Достоевского «Преступление и наказание» // Международный журнал гуманитарных и естественных наук. 2020. № 10. - С. 49-53.

12. Blandy J.M. Moral resolve in three works by Dostoevsky. Oxford University Press. 2021. - $228 \mathrm{p}$.

13. Galounis M. On the Sources of Nihilism in Dostoevsky's «Crime and Punishment». São Paulo. 2020. Vol. 11(16). - P. 237-257. D0l: 10.11606/issn.2317-4765. rus.2020.172012 ISBN: 2317-4765

14. Maslova G. Influence of speech genres on the formation of a language personality in the novel by F.M. Dostoevsky «crime and punishment». Linguistics Journal Research. 2019. Vol.3. - P. 79-82. D0l: 10.25264/2519-2558-2019-8(76)-79-82.

15. Parks T. Feodor Dostoevsky: Crime or Punishment: Writers, Readers, and the Conversations between Them. In book: Life and Work. 2016. - P. 24-47. DOI:10.12987/yale/9780300215366.003.0002

16. Robinson J.E. The spiritual essence of crime and punishment in Crime and Punishment and The Brothers Karamazov by Fyodor Dostoevsky. Routledge. 2021. - $328 \mathrm{p}$.

(с) Келеш Дарья Андреевна (solo.dar9294@yandex.ru). 